\title{
Studies of the Atmospheric Chemistry of Energy-Related Volatile Organic Compounds and of their Atmospheric Reaction Products
}

\author{
Award Number DE-FG03-01ER63095 \\ Project ID 0006663 \\ Final Report, March 1, 2001 through August 31, 2005 \\ Roger Atkinson and Janet Arey, Co-Principal Investigators \\ Air Pollution Research Center \\ University of California, Riverside
}

During this contract, the following studies were completed:

\section{Rate Constants for the Gas-Phase Reactions of Alkylnaphthalenes with the OH Radical}

Naphthalene and its $\mathrm{C}_{1}$ - and $\mathrm{C}_{2}$-alkyl derivatives are semi-volatile polycyclic aromatic hydrocarbons (PAH) emitted from combustion sources, including in diesel exhaust. These PAH exist primarily in the gas phase in ambient atmospheres. Based on the literature data-base for naphthalene, 1- and 2-methylnaphthalene and 2,3-dimethylnaphthalene, in the atmosphere the alkylnaphthalenes are subject to degradation by gas-phase reactions with the hydroxyl $(\mathrm{OH})$ radical and, to a lesser extent, with the nitrate $\left(\mathrm{NO}_{3}\right)$ radical. Using a relative rate method, rate constants for the gas-phase reactions of $\mathrm{OH}$ radicals with a series of alkylnaphthalenes have been measured at $298 \pm 2 \mathrm{~K}$ and atmospheric pressure of air. The compounds studied were naphthalene, 1- and 2-methylnaphthalene (1-, 2-MNs), 1- and 2-ethylnaphthalene (1-, 2-ENs), and the 10 dimethylnaphthalene isomers (1,2-, 1,3-, 1,4-, 1,5-, 1,6-, 1,7-, 1,8-, 2,3-, 2,6- and 2,7DMNs). Using 1,2,3- and 1,3,5-trimethylbenzene as reference compounds, a rate constant for the reaction of $\mathrm{OH}$ radicals with naphthalene of $(2.39 \pm 0.09) \times 10^{-11} \mathrm{~cm}^{3}$ molecule $\mathrm{s}^{-1}$ was measured, in excellent agreement with literature data (much of which is from earlier studies from this laboratory). Using naphthalene as the reference compound with the rate constant measured here, the following rate constants were obtained for the alkylnaphthalenes (in units of $10^{-11} \mathrm{~cm}^{3}$ molecule $\mathrm{e}^{-1} \mathrm{~s}^{-1}$ ): $1-\mathrm{MN}, 4.09 \pm 0.20 ; 2-\mathrm{MN}, 4.86 \pm 0.25 ; 1-\mathrm{EN}, 3.64 \pm 0.41 ; 2-\mathrm{EN}, 4.02 \pm 0.55$; 1,2-DMN, $5.96 \pm 0.55$; 1,3-DMN, $7.49 \pm 0.39$; 1,4-DMN, $5.79 \pm 0.36$; 1,5-DMN, $6.01 \pm 0.35$; 1,6-DMN, $6.34 \pm 0.36$; 1,7-DMN, $6.79 \pm 0.45$; 1,8-DMN, $6.27 \pm 0.43$; 2,3-DMN, $6.15 \pm 0.47$; 2,6-DMN, $6.65 \pm 0.35$; and 2,7-DMN, $6.87 \pm 0.43$. These data show that under atmospheric conditions, with an assumed 12-hr daytime $\mathrm{OH}$ radical concentration of $2.0 \times 10^{6}$ molecule $\mathrm{cm}^{-3}$, the DMN isomers react most rapidly with the $\mathrm{OH}$ radical, with calculated lifetimes of 1.9-2.4 hours, followed by the MNs and ENs with lifetimes of 2.9-3.8 hours, and naphthalene with a lifetime of 5.8 hours.

We have observed a "traffic signature" for these alkylnaphthalenes in ambient air samples collected in Riverside, CA, where traffic is expected to be the dominant emission source. Analyses of ambient air samples collected in Riverside, CA, during August 2001 for naphthalene, 1- and 2-methylnaphthalene, 1- and 2-ethylnaphthalene and several dimethylnaphthalenes show a good correlation of the nighttime/daytime naphthalene or alkylnaphthalene concentration ratio with their rate constant for reaction with the $\mathrm{OH}$ radical. 
These ambient data are therefore consistent with the occurrence of a daytime reaction with the $\mathrm{OH}$ radical and with the daytime reaction with $\mathrm{OH}$ radicals being the dominant chemical loss process for naphthalene and the alkylnaphthalenes in the particular airmasses sampled. A manuscript describing this work has been published in Environmental Science \& Technology, 36, 1947-1952 (2002).

\section{Rate Constants for the Gas-Phase Reactions of Alkylnaphthalenes with the $\mathrm{NO}_{3}$ Radical}

In order to fully understand the chemical loss processes of alkylnaphthalenes in the troposphere, we have also measured rate constants for the gas-phase reactions of $\mathrm{NO}_{3}$ radicals with a series of alkylnaphthalenes at $298 \pm 2 \mathrm{~K}$ and atmospheric pressure of air using a relative rate method. The compounds studied were the same as for the $\mathrm{OH}$ radical reactions discussed above. Using naphthalene as the reference compound with a "rate constant" of $3.65 \times 10^{-28} \mathrm{~cm}^{6}$ molecule $\mathrm{e}^{-2} \mathrm{~s}^{-1}$ (see below), the rate constants obtained for the $\mathrm{NO}_{3}$ reactions (in units of $10^{-28} \mathrm{~cm}^{6}$ molecule $\mathrm{e}^{-2} \mathrm{~s}^{-1}$, indicated errors are two least-squares standard deviations) were: $1-\mathrm{MN}, 7.15 \pm$ 0.37; 2-MN, $10.2 \pm$ 1.0; 1-EN, $9.82 \pm 0.69$; 2-EN, $7.99 \pm 0.99$; 1,2-DMN, $64.0 \pm 2.3$; 1,3-DMN, $21.3 \pm 1.2$; 1,4-DMN, $13.0 \pm$ 0.5; 1,5-DMN, $14.1 \pm 1.3$; 1,6-DMN, $16.5 \pm 1.8$; 1,7-DMN, $13.5 \pm$ 0.7; 1,8-DMN, $212 \pm$ 59; 2,3-DMN, $15.2 \pm 0.5$; 2,6-DMN, $21.2 \pm$ 1.6; and 2,7-DMN, $21.0 \pm 1.5$. As discussed previously (Atkinson, J. Phys. Chem. Ref. Data, 20, 459-507, 1991), the measured "rate constants" are really rate constant ratios, $\mathrm{k}_{\mathrm{a}} \mathrm{k}_{\mathrm{c}} / \mathrm{k}_{\mathrm{b}}$, for the elementary reactions (a), (b) and (c).

$\mathrm{NO}_{3}+$ alkylnaphthalene $\rightarrow \mathrm{NO}_{3}$-alkylnaphthalene adduct

$\mathrm{NO}_{3}$-alkylnaphthalene adduct $\rightarrow \mathrm{NO}_{3}+$ alkylnaphthalene

$\mathrm{NO}_{3}$-alkylnaphthalene adduct $+\mathrm{NO}_{2} \rightarrow$ products

$\mathrm{NO}_{3}$-alkylnaphthalene adduct $+\mathrm{O}_{2} \rightarrow$ products

Note that previous work in our laboratory has shown that under laboratory conditions, the reaction of the $\mathrm{NO}_{3}$-naphthalene adduct with $\mathrm{O}_{2}$ [reaction (d)] does not occur and that $\mathrm{k}_{\mathrm{d}} / \mathrm{k}_{\mathrm{c}}$ (naphthalene) $<4 \times 10^{-7}$ at $298 \pm 2 \mathrm{~K}$ (Atkinson et al., Int. J. Chem. Kinet., 26, 605-614, 1994). This rate constant ratio $\mathrm{k}_{\mathrm{d}} / \mathrm{k}_{\mathrm{c}}$ means that reaction of the $\mathrm{NO}_{3}$-naphthalene adduct with $\mathrm{NO}_{2}$ dominates for $\mathrm{NO}_{2}$ mixing ratios $>80 \mathrm{ppb}$ (and possibly much lower because only an upper limit to $\mathrm{k}_{\mathrm{d}} / \mathrm{k}_{\mathrm{c}}$ is available). This is consistent with previous ambient measurements from this laboratory which show enhanced formation of nitronaphthalenes and methylnitronaphthalenes at night in the eastern portion of the Los Angeles air basin, presumed to be from nighttime $\mathrm{NO}_{3}$ radical reactions. Reactions (1) through (3) predict that, as observed in the laboratory, the lifetime of an alkylnaphthalene is inversely proportional to the $\mathrm{NO}_{2}$ concentration. Using reasonable ambient concentrations of $\mathrm{NO}_{3}$ radicals and $\mathrm{NO}_{2}$ representative of an urban area, the calculated lifetimes of the alkylnaphthalenes are longer (often significantly longer) than their corresponding lifetimes due to daytime reaction with the $\mathrm{OH}$ radical. It needs to be recognized, however, that despite the dominance of daytime reaction with the $\mathrm{OH}$ radical as an alkylnaphthalene loss process, the high formation yields of nitro-alkylnaphthalenes from the $\mathrm{NO}_{3}$ radical-initiated reactions mean that the nighttime $\mathrm{NO}_{3}$ radical-initiated reactions can be important in the atmospheric formation of nitro-alkylnaphthalenes. A manuscript describing this 
work has been published in Environmental Science \& Technology, 37, 308-313 (2003).

\section{Photolysis of Nitronaphthalenes and Methylnitronaphthalenes}

Nitro-substituted polycyclic aromatic hydrocarbons (nitro-PAH) are a ubiquitous class of compounds in the ambient atmosphere which are known to be mutagenic and carcinogenic environmental pollutants. 1-Nitronaphthalene (1NN) and 2-nitronaphthalene (2NN), atmospheric transformation products of naphthalene, are among the most abundant gas-phase nitro-PAH measured in ambient atmospheres. The methylnitronaphthalenes (MNN), of which there are 14 possible isomers, are atmospheric transformation products of 1- and 2methylnaphthalene. We have investigated the photolysis rates of $1 \mathrm{NN}, 2 \mathrm{NN}$, and twelve of the MNN isomers, both in an indoor 7000 liter Teflon chamber using blacklamp irradiation and outdoors in a 3000-4000 liter Teflon chamber using natural sunlight. The MNN isomers were synthesized using two methods previously employed in our laboratory: (a) by reaction of the parent PAH with dinitrogen pentoxide in carbon tetrachloride solution at room temperature, and (b) by reaction of the parent PAH with dinitrogen tetroxide in methylene chloride solution at room temperature. These reactions produced different isomer distributions, and we were able to obtain sufficient amounts of 12 of the MNN isomers on which to conduct the photolysis experiments. The photolysis rate of $\mathrm{NO}_{2}$ was also measured, both in the indoor experiments and the outdoor experiments. Problems with wall adsorption/desorption were apparent in the outdoor irradiations, caused (at least in part) by temperature fluctuations in the chamber (these were not apparent in the indoor experiments which used a larger chamber and had the advantage that the blacklamps could be turned off during the analysis period). In order to minimize temperature variations in the outdoor experiments, once the irradiation was initiated by removing an opaque tarpaulin, irradiation was continuous and gas samples were collected for analysis periodically during the irradiation. The measured photolysis rates in the indoor chamber with blacklamp irradiation (at an $\mathrm{NO}_{2}$ photolysis rate of $0.114 \mathrm{~min}^{-1}$ ) in $\mathrm{min}^{-1}$ were: $1 \mathrm{NN}, 0.0151 \pm 0.0017 ; 2 \mathrm{NN}$, $0.0021 \pm 0.0006$; $1 \mathrm{M} 2 \mathrm{NN}, 0.0116 \pm 0.0027$; $1 \mathrm{M} 3 \mathrm{NN}, 0.0052 \pm 0.0020$; $1 \mathrm{M} 4 \mathrm{NN}, 0.0167 \pm$ 0.0037 ; $1 \mathrm{M} 5 \mathrm{NN}, 0.0096 \pm 0.0032 ; 1 \mathrm{M} 6 \mathrm{NN}, 0.0042 \pm 0.0010 ; 1 \mathrm{M} 8 \mathrm{NN}, 0.0617 \pm 0.0231$; $2 \mathrm{M} 1 \mathrm{NN}, 0.0367 \pm 0.0045 ; 2 \mathrm{M} 4 \mathrm{NN}, 0.0088 \pm 0.0030$; 2M5NN, $0.0075 \pm 0.0032 ; 2 \mathrm{M} 6 \mathrm{NN}$, $0.0028 \pm 0.0040$; and 2M8NN, $0.0117 \pm 0.0027$. Gas-phase photolysis appears to depend on molecular structure, with those $\mathrm{NN}$ and MNN with non-planar configuration (i.e., $1 \mathrm{NN}$ and 2M1NN) being less stable towards photolysis.

Taking into account the higher light intensity outdoors (measured NO2 photolysis rate of $0.274 \mathrm{~min}^{-1}$ ), the photolysis rates measured outdoors with natural solar radiation were consistent, within the large uncertainties, with the photolysis rates measured indoors with blacklamp irradiation. The calculated lifetimes (at an average daytime $\mathrm{NO}_{2}$ photolysis rate of $0.31 \mathrm{~min}^{-1}$ ) range from $6 \mathrm{~min}$ for $1 \mathrm{M} 8 \mathrm{NN}$ to $3 \mathrm{hr}$ for 2NN, with the majority of the nitro-alkylnaphthalenes having calculated lifetimes of 20-90 min. These lifetimes due to photolysis are significantly shorter that predicted for either the daytime $\mathrm{OH}$ radical reaction or the nighttime $\mathrm{NO}_{3}$ radical reaction, and hence the dominant loss process of the gaseous nitro-alkylnaphthalenes will be daytime photolysis. A manuscript describing this study has been published in the Journal of Photochemistry and Photobiology A: Chemistry, 157, 301-309 (2003). 


\section{Identification and Quantification of Hydroxycarbonyls from the $\mathrm{OH}$ Radical-Initiated Reactions of Selected Biogenic Compounds.}

The products formed from the gas-phase reactions of volatile organic compounds (VOCs) with $\mathrm{OH}$ radicals, $\mathrm{NO}_{3}$ radicals and $\mathrm{O}_{3}$ include hydroxycarbonyls. However, hydroxyaldehydes do not elute from gas chromatographic columns without prior derivatization. We have completed our study of the gas-phase reactions of $\mathrm{OH}$ radicals with the biogenic VOCs 2methyl-3-buten-2-ol $\left[\left(\mathrm{CH}_{3}\right)_{2} \mathrm{C}(\mathrm{OH}) \mathrm{CH}=\mathrm{CH}_{2}\right]$ and cis-3-hexen-1-ol $\left[\mathrm{CH}_{3} \mathrm{CH}_{2} \mathrm{CH}=\mathrm{CHCH}_{2} \mathrm{CH}_{2} \mathrm{OH}\right]$. We used Solid Phase Micro Extraction (SPME) fibers coated with $O$-(2,3,4,5,6-pentafluorobenzyl)hydroxylamine hydrochloride for on-fiber derivatization of carbonyl compounds (to form their oxime derivative), with subsequent thermal desorption and analysis of the oximes by combined gas chromatography-mass spectrometry (GC-MS) and gas chromatography with flame ionization detection (GC-FID) in order to identify and quantify the hydroxycarbonyl products of these reactions. In order to quantify the hydroxyaldehydes, we measured the GC-FID "response factors" of $30 \mathrm{C}_{3}-\mathrm{C}_{8}$ carbonyl-containing compounds (ketones, aldehydes and hydroxycarbonyls) introduced into a 7500 liter volume Teflon chamber at approximately 100-300 ppb mixing ratio in air and analyzed as their oximes using the coated SPME fiber method. These GC-FID response factors indicate that (a) the response increases with carbon number over this range $\left(\mathrm{C}_{3}-\mathrm{C}_{8}\right)$, (b) for a given carbon number, the response increases along the series $\mathrm{RC}(\mathrm{O}) \mathrm{CH}_{2} \mathrm{CH}_{2} \mathrm{CH}_{3}<\mathrm{RC}(\mathrm{O}) \mathrm{CH}_{2} \mathrm{CH}_{3}<\mathrm{RC}(\mathrm{O}) \mathrm{CH}_{3}<\mathrm{RCHO}$, and (c) hydroxycarbonyls have a higher response than do carbonyls of the same carbon number, with the response factor for a hydroxycarbonyl being a factor of 5.1 higher than that of the carbonyl compound which has the $\mathrm{OH}$ group replaced by a $\mathrm{CH}_{3}$ group. This procedure allows estimation of response factors for hydroxyaldehydes for which standards are not available and which cannot be analyzed without prior derivatization.

GC-MS analyses of irradiated $\mathrm{CH}_{3} \mathrm{ONO}$ - $\mathrm{NO}$ - cis-3-hexen-1-ol - air and $\mathrm{CH}_{3} \mathrm{ONO}$ NO - 2-methyl-3-buten-2-ol - air mixtures, using coated SPME fibers for on-fiber derivatization with subsequent thermal desorption, showed the presence of oximes of propanal and of a carbonyl-containing product of molecular weight 74 from the cis-3-hexen-1-ol reaction, and of oximes of glycolaldehyde [ $\mathrm{HOCH}_{2} \mathrm{CHO}$ ] and of a carbonyl-containing compound of molecular weight 88 from the 2-methyl-3-buten-2-ol reaction. On the basis of previous studies of these reactions in our laboratory, the molecular weight 74 and 88 products are attributed to 3hydroxypropanal [ $\mathrm{HOCH}_{2} \mathrm{CH}_{2} \mathrm{CHO}$ ] from cis-3-hexen-1-ol and 2-hydroxy-2-methylpropanal $\left[\left(\mathrm{CH}_{3}\right)_{2} \mathrm{C}(\mathrm{OH}) \mathrm{CHO}\right]$ from 2-methyl-3-buten-2-ol. GC-FID analyses of the oximes of carbonyl compounds (formed by on-fiber derivatization) from the reaction mixtures resulted in formation yields (after minor correction for reactions of the products with $\mathrm{OH}$ radicals) of $101 \pm 24 \%$ for formation of 3-hydroxypropanal from cis-3-hexen-1-ol and $31 \pm 4 \%$ for formation of 2-hydroxy2-methylpropanal from 2-methyl-3-buten-2-ol. These formation yields are in reasonable or good agreement with the formation yields of the expected co-products measured by Aschmann et al. (1997) [74.6 \pm 6.7\% for formation of propanal from cis-3-hexen-1-ol] and Alvarado et al. (1999) [29 $\pm 3 \%$ for formation of HCHO from 2-methyl-3-buten-2-ol]. We also used in situ atmospheric pressure ionization mass spectrometry (API-MS) for analysis of these hydroxycarbonyls, with detection of the hydroxycarbonyls as their $\mathrm{NO}_{2}{ }^{-}$adducts. Hydroxycarbonyl standards with similar chemical structures were used as internal standards (added after the reactions) and equal sensitivities of the $\mathrm{NO}_{2}{ }^{-}$adducts were assumed to allow quantification. Using API-MS analyses, we observed the expected hydroxycarbonyls 2-hydroxy2-methylpropanal from 2-methyl-3-buten-2-ol and 3-hydroxypropanal from cis-3-hexen-1-ol as 
their $\mathrm{NO}_{2}{ }^{-}$adducts, and obtained formation yields of $44 \%$ for formation of 3-hydroxypropanal from cis-3-hexen-1-ol and 16\% for formation of 2-hydroxy-2-methylpropanal from 2-methyl-3buten-2-ol. We also observed the dihydroxynitrates attributed to $\left(\mathrm{CH}_{3}\right)_{2} \mathrm{C}(\mathrm{OH}) \mathrm{CH}\left(\mathrm{ONO}_{2}\right) \mathrm{CH}_{2} \mathrm{OH}$ from 2-methyl-3-buten-2-ol and $\mathrm{CH}_{3} \mathrm{CH}_{2} \mathrm{CH}(\mathrm{OH}) \mathrm{CH}\left(\mathrm{ONO}_{2}\right) \mathrm{CH}_{2} \mathrm{CH}_{2} \mathrm{OH}$ from cis-3-hexen-1-ol (and/or their isomers) as their $\mathrm{NO}_{2}{ }^{-}$adducts. These product data indicate that for the cis-3-hexen-1-ol reaction, 3hydroxypropanal is formed together with propanal, and we can now account for $75 \pm 7 \%$ of the reaction products, with an observed dihydroxycarbonyl and dihydroxynitrates accounting for some or all of the remainder. For the 2-methyl-3-buten-2-ol reaction, our data indicate that 2hydroxy-2-methylpropanal is formed together with $\mathrm{HCHO}$ and we can account for essentially all ( $92 \pm 6 \%$ ) of the reaction products. This study has been published in Environmental Science \& Technology, 37, 4664-4671 (2003).

\section{Presence and Sources of 2- and 3-Nitrobenzanthrone in Ambient Air}

3-Nitrobenzanthrone is a powerful bacterial mutagen which was identified by Japanese scientists in diesel emission and ambient particle extracts, and it was suggested that atmospheric reactions of benzanthrone may be responsible for the presence of this compound in ambient air. We synthesized both 2- and 3-nitrobenzanthrone (by reaction of benzanthrone with $\mathrm{N}_{2} \mathrm{O}_{5}$ in $\mathrm{CCl}_{4}$ solution and with $\mathrm{N}_{2} \mathrm{O}_{4}$ in $\mathrm{CH}_{2} \mathrm{Cl}_{2}$ solution, respectively) and conclusively identified them by ${ }^{1} \mathrm{H}-$ NMR. Chamber reactions of gaseous benzanthrone (introduced into the chamber by spraying a solution of benzanthrone in methanol into the chamber prior to the experiments) with $\mathrm{OH}$ radicals and $\mathrm{NO}_{3}$ radicals formed essentially only 2-nitrobenzanthrone in each case (a very small amount of 3-nitrobenzanthrone was observed in the $\mathrm{NO}_{3}$ radical reaction, but this could have arisen from wall reactions). GC-MS SIM analyses of a diesel particle extract (NIST SRM 1975) showed the presence of mainly 3-nitrobenzanthrone (generally diesel and combustion emissions contain isomers identical to the electrophilic nitration products), while GC-MS SIM analyses of an ambient particle extract from filters collected during daytime in Concord, CA, showed the presence of mainly 2-nitrobenzanthrone. These data indicate that benzanthrone is analogous to fluoranthene, in that atmospheric $\mathrm{OH}$ and $\mathrm{NO}_{3}$ radical-initiated reactions lead to the 2-nitroisomer, while electrophilic reactions lead to formation of the 3-nitro-isomer. The presence of 2nitrobenzanthrone in ambient air particle extracts thus shows the importance of atmospheric formation via $\mathrm{OH}$ and/or $\mathrm{NO}_{3}$ radical-initiated reactions. This work has been published in Atmospheric Environment, 37, 3189-3199 (2003).

\section{Products of the Gas-Phase Reaction of $\mathrm{O}_{3}$ with Selected Alkenes}

The reactions of $\mathrm{O}_{3}$ with alkenes proceed by initial addition to form a "primary ozonide", which rapidly decomposes to, typically, two sets of "primary" carbonyl + Criegee intermediate. For cyclic alkenes with internal double bond(s) such as alpha-pinene, the primary ozonide decomposes to typically two carbonyl-substituted Criegee intermediates. Mono-alkyl substituted Criegee intermediates exist in the syn- and anti-configuration, and it is now believed that the excited and thermalized syn-intermediates can isomerize to a hydroperoxide which decomposes to form an $\mathrm{OH}$ radical, as for example,

$\left[\left(\mathrm{CH}_{3}\right)_{2} \mathrm{COO}\right]^{*} \rightarrow\left[\mathrm{CH}_{3} \mathrm{C}(\mathrm{OOH})=\mathrm{CH}_{2}\right] \rightarrow \mathrm{CH}_{3} \mathrm{C}(\mathrm{O}) \mathrm{CH}_{2}+\mathrm{OH}$ 
In contrast, the anti-intermediates cannot undergo this isomerization to any extent, and are therefore collisionally stabilized. They are then expected to react with water vapor under atmospheric conditions to form an $\alpha$-hydroxyhydroperoxide, which may decompose by two routes.

$$
\begin{aligned}
& \mathrm{CH}_{3} \mathrm{CHOO}+\mathrm{H}_{2} \mathrm{O} \rightarrow \mathrm{CH}_{3} \mathrm{CH}(\mathrm{OH}) \mathrm{OOH} \\
& \mathrm{CH}_{3} \mathrm{CH}(\mathrm{OH}) \mathrm{OOH} \rightarrow \mathrm{CH}_{3} \mathrm{C}(\mathrm{O}) \mathrm{OH}+\mathrm{H}_{2} \mathrm{O} \\
& \mathrm{CH}_{3} \mathrm{CH}(\mathrm{OH}) \mathrm{OOH} \rightarrow \mathrm{CH}_{3} \mathrm{CHO}+\mathrm{H}_{2} \mathrm{O}_{2}
\end{aligned}
$$

It has been shown that alcohols such as methanol, propanol and butanol also react with the thermalized Criegee intermediates to form analogous alkoxyhydroperoxides.

We have previously used 2-butanol as an $\mathrm{OH}$ radical scavenger to determine the yields of $\mathrm{OH}$ radicals from the reactions of $\mathrm{O}_{3}$ with alkenes (Chew and Atkinson, J. Geophys. Res., 101, 28649-28653, 1996), from the amount of 2-butanone formed. If OH radicals are formed from isomerization/decomposition of thermalized Criegee intermediates, then one may expect that the $\mathrm{OH}$ radical yield will decrease if the Criegee intermediate(s) are scavenged by reaction with, for example, 2-butanol. Additionally, because the reactions of Criegee intermediates with water vapor lead to formation (at least in part) of a carbonyl, then the yield of this carbonyl should decrease if the Criegee intermediate is scavenged by reaction with compounds other than water vapor. We have investigated the effects of varying the 2-butanol concentration (from $4.3 \times 10^{15}$ molecule $\mathrm{cm}^{-3}$ to $1.32 \times 10^{17}$ molecule $\mathrm{cm}^{-3}$ ), at water vapor concentrations varying from $5 \%$ or less relative humidity to approximately $60 \%$ relative humidity, on selected products formed from the reactions of $\mathrm{O}_{3}$ with sabinene, $\alpha$-pinene and trans-7-tetradecene. The results obtained are briefly discussed below:

Sabinene. In the majority of experiments, 2-butanol was used as the $\mathrm{OH}$ radical scavenger, thereby allowing the $\mathrm{OH}$ radical formation yield to be determined from the amounts of 2butanone formed. The 2-butanol concentrations were varied from $4.4 \times 10^{15}$ to $6.6 \times 10^{16}$ molecule $\mathrm{cm}^{-3}$. At the lower concentrations of added 2-butanol, in the initial stages of the reaction $8 \%$ of the $\mathrm{OH}$ radicals formed would not be scavenged by 2-butanol (rather reacting with sabinene). Hence for these experiments, the measured $\mathrm{OH}$ radical yields are about $10 \%$ too low. In those experiments where 2-butanol was not added, cyclohexane or n-octane were used to scavenge $>95 \%$ of the $\mathrm{OH}$ radicals formed. Sabinaketone is both a "primary" carbonyl and can be formed from reaction of the $\mathrm{C}_{9}$-Criegee intermediates with water vapor (see above). The sabinaketone yield increased with relative humidity (over the range $<5 \%$ to $61 \%$ ), and this is consistent with reaction of the $\mathrm{C}_{9}$-Criegee intermediate with water vapor to form sabinaketone being in competition with reaction of the Criegee intermediate with other species, presumably mainly carbonyls (including formaldehyde) to form secondary ozonides. This behavior is analogous to that observed by other research groups for the beta-pinene and methylenecyclohexane reactions ( $\beta$-pinene, sabinene and methylene-cyclohexane all have an exo-cyclic $=\mathrm{CH} 2$ group). Interestingly, the sabinaketone yield also increases with increasing concentration of 2-butanol (2-butanol being varied from none present (cyclohexane or n-octane then being present to scavenge $\mathrm{OH}$ radicals) to $6.6 \times 10^{16}$ molecule $\mathrm{cm}^{-3}$ at $<5 \%$ relative humidity), suggesting that 2-butanol behaves like water vapor and reacts with the $\mathrm{C}_{9}$-Criegee intermediate to form sabinaketone. The $\mathrm{OH}$ radical formation yield, as derived from 2-butanone formation, 
was independent of water vapor concentration (over the range $<5$ to $61 \%$ relative humidity), but increased from approximately 0.28 to approximately 0.40 as the 2-butanol concentration increased. As noted above, the measured $\mathrm{OH}$ radical formation yield at the lowest added 2butanol concentration is slightly low because of incomplete scavenging of $\mathrm{OH}$ radicals, and the “corrected" increase in $\mathrm{OH}$ radical yield with increasing 2-butanol is from 0.30 to 0.40 . This observed increase in $\mathrm{OH}$ yield (derived from the 2-butanone formation yields) may be due to artifact formation of 2-butanone from 2-butanol in the presence of $\mathrm{O}_{3}$, either from a slow $\mathrm{O} 3$ reaction with 2-butanol (homo- or heterogeneous) or from reactive impurities in the 2-butanol, both becoming more important at higher 2-butanol concentrations.

$\alpha$-Pinene. For the $\alpha$-pinene reaction, pinonaldehyde can only arise from reaction of the Criegee intermediate(s) with water vapor. The measured pinonaldehyde yield was independent of both water vapor ( $<5 \%$ to $59 \%$ relative humidity) and 2-butanol (zero to $1.32 \times 10^{17}$ molecule $\mathrm{cm}^{-3}$ ) concentrations, with an average value of $0.15 \pm 0.02$, where the indicated errors are two leastsquares standard deviations combined with an estimated uncertainty in the GC-FID response factor for pinonaldehyde relative to that for $\alpha$-pinene of $\pm 10 \%$. These observations are in agreement with our previous published data showing no dependence on the pinonaldehyde yield with water vapor nor on changing from cyclohexane to 2-butanol as the $\mathrm{OH}$ radical scavenger.

The $\mathrm{OH}$ formation yield, as derived from the 2-butanone formation, was independent of water vapor concentration ( $<5 \%$ to $59 \%$ relative humidity) but increased with 2-butanol concentration, analogous to the situation in the sabinene reaction (see above).

7-Tetradecene. Heptanal is a primary carbonyl as well as potentially being formed from the Criegee intermediate by reaction with water vapor. The heptanal yield was independent of 2butanol concentration, but increased slightly (by about 20\%) with increasing water vapor concentration ( $<5$ to $60 \%$ relative humidity). The $\mathrm{OH}$ radical yield, as derived from the 2butanone formation yield, was either invariant of 2-butanol concentration or decreased very slightly with increasing 2-butanol concentration (decreasing from 0.25 to 0.20 as the 2-butanol concentrations increased from $4.4 \times 10^{15}$ to $6.6 \times 10^{16}$ molecule $\mathrm{cm}^{-3}$ ), and appeared to decrease slightly (from 0.25 to 0.20 ) as the relative humidity increased from $5 \%$ to $60 \%$. Note that 7 tetradecene is expected to be significantly more reactive towards $\mathrm{O}_{3}$ than are sabinene and $\alpha$ pinene, and hence 2-butanol would be exposed to much less ozone in this reaction system than in the sabinene and $\alpha$-pinene reactions, with less chance of artifact formation of 2-butanone (as observed).

Our data from these three alkenes provide no convincing evidence that decomposition of the Criegee intermediates to form an $\mathrm{OH}$ radical is in competition with other reactions of the Criegee intermediates, except possibly in the 7-tetradecene reaction. The invariance of the pinonaldehyde yield from $\alpha$-pinene with the 2-butanol concentration shows that reactions of the C9-Criegee intermediate with 2-butanol do not compete with reaction of the Criegee intermediate with water vapor [the only reaction leading to pinonaldehyde] unless reaction with 2-butanol can also lead to pinonaldehyde formation. It seems that, at least for the reactions investigated here, $\mathrm{OH}$ radicals can be viewed as being almost totally formed from chemically activated Criegee intermediates [reaction (1)]. 
Formation of Methylglyoxal from the $\mathrm{OH}$ Radical-Initiated Reaction of 3-Hexene-2,5-dione

3 -Hexene-2,5-dione $\left[\mathrm{CH}_{3} \mathrm{C}(\mathrm{O}) \mathrm{CH}=\mathrm{CHC}(\mathrm{O}) \mathrm{CH}_{3}\right]$ is formed in significant yield from the atmospheric reactions of $p$-xylene and 1,2,4-trimethylbenzene (Bethel et al., J. Phys. Chem. A, 104, 8922-8929, 2000). In the atmosphere, 3-hexene-2,5-dione photolyzes rapidly (mainly by cis-/trans- isomerization) and also reacts rapidly with $\mathrm{OH}$ radicals. Two previous product studies of the $\mathrm{OH}$ radical-initiated reaction of 3-hexene-2,5-dione, both using in situ Fourier transform infrared (FT-IR) spectroscopy, provided conflicting data concerning the formation yield of methylglyoxal. Tuazon et al. (Environ. Sci. Technol., 19, 265-269, 1985) did not observe methylglyoxal formation (with a molar yield of $<10-15 \%$ ), while Bierbach et al. (Environ. Sci. Technol., 28, 715-729, 1994) reported that methylglyoxal accounted for $30 \%$ of the carbon balance (hence a molar yield of 60\%). Recently, we used in situ API-MS for analysis of the products of this reaction and observed the formation of products of molecular weight 102 and 191, attributed to $\mathrm{CH}_{3} \mathrm{C}(\mathrm{O}) \mathrm{CH}(\mathrm{OH}) \mathrm{CHO}$ and the hydroxynitrate $\mathrm{CH}_{3} \mathrm{C}(\mathrm{O}) \mathrm{CH}(\mathrm{OH}) \mathrm{CH}\left(\mathrm{ONO}_{2}\right) \mathrm{C}(\mathrm{O}) \mathrm{CH}_{3}$, respectively (Bethel et al., Environ. Sci. Technol., 35, 4477-4480, 2001). However, no quantification of these products was possible. We have therefore re-investigated the formation of methylglyoxal from irradiated $\mathrm{CH}_{3} \mathrm{ONO}-\mathrm{NO}$ - 3hexene-2,5-dione - air mixtures using in situ FT-IR spectroscopy, with a much improved data system compared to that in our earlier study (Tuazon et al., 1985). These experiments show that methylglyoxal is, at most, a minor product with a molar formation yield of $<10 \%$ (and most likely $<1 \%$ ). This confirms our previous API-MS study and suggests that $\mathrm{CH}_{3} \mathrm{C}(\mathrm{O}) \mathrm{CH}(\mathrm{OH}) \mathrm{CHO}$ and $\mathrm{CH}_{3} \mathrm{C}(\mathrm{O}) \mathrm{CH}(\mathrm{OH}) \mathrm{CH}\left(\mathrm{ONO}_{2}\right) \mathrm{C}(\mathrm{O}) \mathrm{CH}_{3}$ are the major first-generation products. This work has been published in Environmental Science and Technology, 37, 33393341 (2003).

\section{Formation and Reactions of Hydroxyaldehydes from the OH Radical-Initiated Reactions of 1,3-Butadiene and Isoprene}

Previous studies of the products formed from the reactions of $\mathrm{OH}$ radicals with 1,3butadiene and isoprene (in the presence of NO) accounted for only about $65 \%$ of the products. The remaining products have been tentatively identified by API-MS studies in this laboratory as hydroxyaldehydes formed by isomerization of, for example, the $\mathrm{HOCH}_{2} \mathrm{CH}=\mathrm{CHCH}_{2} \mathrm{O}$ hydroxyalkoxy radical formed in the 1,3-butadiene reaction, leading to $\mathrm{HOCH}_{2} \mathrm{CH}=\mathrm{CHCHO}$. These unsaturated hydroxyaldehydes are not commercially available, and do not appear to elute from GC columns unless they have been derivatized prior to injection onto the GC column. We have therefore used SPME with on-fiber derivatization to monitor the hydroxyaldehydes formed from the reactions of $\mathrm{OH}$ radicals with 1,3-butadiene and isoprene. Based on the reactions (taking 1,3-butadiene as an example)

$\mathrm{OH}+1$,3-butadiene $\rightarrow \alpha$ hydroxyaldehyde

$\mathrm{OH}+$ hydroxyaldehyde $\rightarrow$ products

then by monitoring the hydroxyaldehyde concentration as a function of the extent of reaction the rate constant ratio $\mathrm{k}_{2} / \mathrm{k}_{1}$ can be derived. The value of $\ln \left([1,3 \text {-butadiene }]_{\text {initial }} /[1,3 \text {-butadiene }]_{\text {time }=t}\right)$ at which the hydroxyaldehyde concentration is a maximum is determined only by the rate constant ratio $\mathrm{k}_{2} / \mathrm{k}_{1}$ and hence, in conjunction with visual fitting of the entire experimentally 
measured [hydroxyaldehyde] versus $\ln \left([1,3 \text {-butadiene }]_{\text {initial }} /[1,3 \text {-butadiene }]_{\text {time }=t}\right)$ profile against calculated profiles, the rate constant ratios $\mathrm{k}_{2} / \mathrm{k}_{1}$ were derived (to approximately $\pm 25-30 \%$ ).

One hydroxyaldehyde of molecular weight 86 was observed (as its oxime) from the 1,3butadiene reaction, and attributed to $\mathrm{HOCH}_{2} \mathrm{CH}=\mathrm{CHCHO}$, while two hydroxycarbonyls of molecular weight 100 were observed (as their oximes) from the isoprene reaction, and attributed to $\mathrm{HOCH}_{2} \mathrm{C}\left(\mathrm{CH}_{3}\right)=\mathrm{CHCHO}$ and $\mathrm{HOCH}_{2} \mathrm{CH}=\mathrm{C}\left(\mathrm{CH}_{3}\right) \mathrm{CHO}$. Unfortunately, at this time we are unable to distinguish between the molecular weight 100 products. From the "time-dependence" profiles of the hydroxyaldehydes and the recommended rate constants $\mathrm{k}_{1}$, a room temperature rate constant for the reaction of $\mathrm{OH}$ radicals with $\mathrm{HOCH}_{2} \mathrm{CH}=\mathrm{CHCHO}$ of $(5.7 \pm 1.4) \times 10^{-11} \mathrm{~cm}^{3}$ molecule $\mathrm{s}^{-1} \mathrm{~s}^{-1}$ was obtained, and rate constants of $4 \times 10^{-11} \mathrm{~cm}^{3}$ molecule $\mathrm{s}^{-1}$ and $1.0 \times 10^{-10} \mathrm{~cm}^{3}$ molecule $\mathrm{e}^{-1} \mathrm{~s}^{-1}$ were obtained for the reactions of the $\mathrm{OH}$ radical with $\mathrm{HOCH}_{2} \mathrm{C}\left(\mathrm{CH}_{3}\right)=\mathrm{CHCHO}$ and $\mathrm{HOCH}_{2} \mathrm{CH}=\mathrm{C}\left(\mathrm{CH}_{3}\right) \mathrm{CHO}$ (but we do not know which rate constant goes with which hydroxyaldehyde in this case). Using two fibers (a "flexible" fiber and a "rigid" fiber) and an estimated response factor for the GC-FID analysis of the oximes of $\mathrm{HOCH}_{2} \mathrm{CH}=\mathrm{CHCHO}$ (the same for each fiber based on response factors for a series of other carbonyl-containing compounds) leads to a formation yield of $\mathrm{HOCH}_{2} \mathrm{CH}=\mathrm{CHCHO}$ from the reaction of $\mathrm{OH}$ radicals with 1,3-butadiene of $25(+15 /-10) \%$. Combined with previous product data from our laboratory (Tuazon et al., Environ. Sci. Technol., 33, 3586-3595, 1999) we can now account for $90 \pm 15 \%$ of the reaction products from the 1,3-butadiene reaction.

For the isoprene reaction, the derivation of the yields $\mathrm{HOCH}_{2} \mathrm{C}\left(\mathrm{CH}_{3}\right)=\mathrm{CHCHO}$ and $\mathrm{HOCH}_{2} \mathrm{CH}=\mathrm{C}\left(\mathrm{CH}_{3}\right) \mathrm{CHO}$ is less certain because we do not know which set of GC peaks correspond to the oxime of which hydroxyaldehyde; the sum of the yields of the two $\mathrm{C}_{5}$ hydroxyaldehydes appears to be in the region of $\sim 15 \%$ or less. This work has been published in Environmental Science \& Technology, 39, 4091-4099 (2005).

\section{Rate Constants for the Reaction of $\mathrm{OH}$ Radicals with a Series of Hydroxyaldehdyes}

As noted above, apart from glycolaldehyde $\left[\mathrm{HOCH}_{2} \mathrm{CHO}\right]$ no hydroxyaldehydes are commercially available and they do not elute from GC columns without prior derivatization. We have determined rate constants at room temperature for the hydroxyaldehydes $\mathrm{CH}_{3} \mathrm{CH}_{2} \mathrm{CH}(\mathrm{OH}) \mathrm{CHO}, \mathrm{CH}_{3} \mathrm{CH}(\mathrm{OH}) \mathrm{CH}_{2} \mathrm{CHO}, \mathrm{CH}_{3} \mathrm{CH}(\mathrm{OH}) \mathrm{CHO},\left(\mathrm{CH}_{3}\right)_{2} \mathrm{C}(\mathrm{OH}) \mathrm{CHO}$ and $\mathrm{HOCH}_{2} \mathrm{CH}_{2} \mathrm{CHO}$ by monitoring the concentrations of these hydroxyaldehdyes (as their oximes) using SPME with on-fiber derivatization during the $\mathrm{CH}_{3} \mathrm{ONO}$ - $\mathrm{NO}$ - air irradiations of 1,2butanediol, 1,3-butanediol, 2-methyl-2,4-pentanediol, 2-methyl-3-buten-2-ol and cis-3-hexen-1ol, respectively. The rate constants were obtained relative to those for the precursor compounds as described above, and in units of $10^{-12} \mathrm{~cm}^{3}$ molecule ${ }^{-1} \mathrm{~s}^{-1}$ are: $\mathrm{CH}_{3} \mathrm{CH}_{2} \mathrm{CH}(\mathrm{OH}) \mathrm{CHO}, 23.7 \pm$ 2.3; $\mathrm{CH}_{3} \mathrm{CH}(\mathrm{OH}) \mathrm{CH}_{2} \mathrm{CHO}, 29.5 \pm 2.4 ; \mathrm{CH}_{3} \mathrm{CH}(\mathrm{OH}) \mathrm{CHO}, 17.0 \pm 2.0 ;\left(\mathrm{CH}_{3}\right)_{2} \mathrm{C}(\mathrm{OH}) \mathrm{CHO}, 14.0 \pm$ 2.5; and $\mathrm{HOCH}_{2} \mathrm{CH}_{2} \mathrm{CHO}, 19.9 \pm 2.9$. In addition, rate constants were obtained for $\mathrm{HOCH}_{2} \mathrm{CHO}, \mathrm{CH}_{3} \mathrm{CH}_{2} \mathrm{C}(\mathrm{O}) \mathrm{CH}_{2} \mathrm{OH}, \mathrm{CH}_{3} \mathrm{C}(\mathrm{O}) \mathrm{CH}_{2} \mathrm{CH}_{2} \mathrm{OH},\left(\mathrm{CH}_{3}\right)_{2} \mathrm{C}(\mathrm{OH}) \mathrm{CH}_{2} \mathrm{C}(\mathrm{O}) \mathrm{CH}_{3}$ and $\mathrm{CH}_{3} \mathrm{CH}_{2} \mathrm{CHO}$, all of which are in reasonable agreement (within the fitting uncertainties) with previous literature data. This work has been published in the Journal of Physical Chemistry A, 108, 7032-7037 (2004). 


\section{Reaction of Cl Atoms with Aromatic Hydrocarbons and Polycyclic Aromatic Hydrocarbons (PAH)}

Reactions of $\mathrm{Cl}$ atoms with organic compounds have been proposed as being of potential importance in coastal areas, because of the formation of active chlorine-containing compounds from sea-salt aerosol, leading to $\mathrm{Cl}$ atom formation during daylight hours. To assess whether or not $\mathrm{Cl}$ atom reactions with $\mathrm{PAH}$ are of any importance, we have used a relative rate method to measure rate constants for the reactions of $\mathrm{Cl}$ atoms with naphthalene, 1- and 2methylnaphthalene, 1- and 2-ethylnaphthalene and all 10 of the dimethylnaphthalenes at room temperature. Kinetic experiments were carried out in air in the absence of $\mathrm{NO}_{\mathrm{x}}$, with $\mathrm{Cl}$ atoms being generated by the photolysis of $\mathrm{Cl}_{2}$. To ensure that any $\mathrm{OH}$ radicals formed did not contribute to the measured disappearance rates of the reference compound and alkylnaphthalenes, a large excess of benzene was included in the reactant mixtures. 1,3,5Trimethylbenzene was used as the reference compound, and its rate constant was measured relative to those for toluene and the three xylene isomers. Based on a rate constant for the reaction of $\mathrm{Cl}$ atoms with 1,3,5-trimethylbenzene of $2.42 \times 10^{-10} \mathrm{~cm}^{3}$ molecule $\mathrm{s}^{-1}$ (derived from the literature rate data for toluene and the three xylene isomers and our relative rate data), the rate constants for the methyl-, ethyl- and dimethylnaphthalenes range from $1.05 \times 10^{-10} \mathrm{~cm}^{3}$ molecule $^{-1} \mathrm{~s}^{-1}$ (for 2-methylnaphthalene) to $3.61 \times 10^{-10} \mathrm{~cm}^{3}$ molecule $^{-1} \mathrm{~s}^{-1}$ (for 1,2dimethylnaphthalene) Naphthalene is unreactive, with an upper limit to its rate constant of $\leq 9.1$ x $10^{-13} \mathrm{~cm}^{3}$ molecule $\mathrm{s}^{-1}$. Rate constants were also measured for toluene- $\mathrm{d}_{8}$ and 1 methylnaphthalene- $\mathrm{d}_{10}$, relative to those for toluene and 1-methylnaphthalene, respectively, resulting in deuterium isotope effects of $1.42 \pm 0.11$ for toluene versus toluene- $\mathrm{d}_{8}$ and $1.30 \pm$ 0.05 for 1 -methylnaphthalene versus 1 -methylnaphthalene- $\mathrm{d}_{10}$. These kinetic data, and the deuterium isotope effects for toluene and 1-methylnaphthalene, imply that the reactions proceed by $\mathrm{H}$-atom abstraction from the substituent $\mathrm{CH}_{3}$ or $\mathrm{C}_{2} \mathrm{H}_{5}$ groups. The products observed and their formation yields (benzaldehyde ( $84 \pm 7 \%$ ) and benzyl alcohol $(11 \pm 2 \%)$ from toluene and 1-napthaldehyde ( $\geq 36 \pm 15 \%)$ and 1-naphthyl alcohol ( $\geq 12 \pm 14 \%$ ) from 1-metrhylnaphthalene) support the conclusions from the kinetic data that these $\mathrm{Cl}$ atom reactions proceed by $\mathrm{H}$-atom abstraction from the alkyl substituent groups. This work has been published in Environmental Science \& Technology, 39, 5302-5310 (2005).

\section{Glyoxal Formation from the Reactions of $\mathrm{OH}$ Radicals with Naphthalene, Acenaphthylene and Acenaphthene}

We have previously investigated the products formed from the reactions of $\mathrm{OH}$ radicals (in the presence of NOx) with naphthalene, acenaphthene and acenaphthylene. While we obtained a reasonably good carbon balance for the naphthalene reaction [67 $\pm 11 \%$, with 2formylcinnamaldehyde being the major product with a yield of $35(+10 /-5) \%]$ (Sasaki et al., Environ. Sci. Technol., 31, 3173-3179, 1997), much lower carbon balances were obtained for the acenaphthene (the only product quantified being a ring-opened dicarbonyl of molecular weight 160, with a yield of $14-37 \%$ depending on the analysis method) and acenaphthylene (no products quantified) reactions (Reisen and Arey, Environ. Sci. Technol., 36, 4302-4311, 2002). To investigate whether or not the low yield of the ring-opened dicarbonyl from the acenaphthene reaction was due to wall losses of this product and/or analysis problems, we used SPME with onfiber derivatization to measure the formation yield of glyoxal, $(\mathrm{CHO})_{2}$, from these reactions (glyoxal being the expected co-product of the molecular weight 160 dicarbonyl from the acenaphthene reaction). The glyoxal yields obtained are: from naphthalene, approximately $7 \%$ 
(with glyoxal also clearly being formed as a second-generation product from reactions of, for example, 2-formylcinnamaldehyde); from acenaphthene, $12 \%$; and from acenaphthylene, $<3 \%$. The glyoxal yield from the acenaphthene reaction is in the same range as the measured yields of the molecular weight 160 ring-opened dicarbonyl, suggesting that these are co-products and further suggesting that wall losses of the molecular weight 160 dicarbonyl were not occurring and that other products make up the majority of the product carbon balance (and similarly for the acenaphthylene reaction).

\section{Rate Constants for the Gas-Phase Reactions of $\mathrm{OH}$ and $\mathrm{NO}_{3}$ Radicals and $\mathrm{O}_{3}$ with Three Monoterpene Reaction Products}

In previous studies we have shown the formation of 4-methylenehex-5-enal $\left[\mathrm{CH}_{2}=\mathrm{CHC}\left(=\mathrm{CH}_{2}\right) \mathrm{CH}_{2} \mathrm{CH}_{2} \mathrm{CHO}\right]$, cis- and trans-4-methylhexa-3,5-dienal $\left[\mathrm{CH}_{2}=\mathrm{CHC}\left(\mathrm{CH}_{3}\right)=\mathrm{CHCH}_{2} \mathrm{CHO}\right]$ and 4-methylcyclohex-3-en-1-one from the $\mathrm{OH}$ radical- and $\mathrm{O}_{3}$-initiated reactions of myrcene, cis- and trans-ocimene, and terpinolene, respectively. We have synthesized these monoterpene reaction products, identified them by ${ }^{1} \mathrm{H} \mathrm{NMR}$, and measured the rate constants for their gas-phase reactions with $\mathrm{OH}$ and $\mathrm{NO}_{3}$ radicals and $\mathrm{O}_{3}$. These rate constants were determined using relative rate methods, and the rate constants (in $\mathrm{cm}^{3}$ molecule $\left.\mathrm{e}^{-1} \mathrm{~s}^{-1}\right)$ were: 4-methylenehex-5-enal, $(1.55 \pm 0.15) \times 10^{-10},(4.75 \pm 0.35) \times 10^{-13}$ and $(1.46$ $\pm 0.12) \times 10^{-17}$ for reactions with $\mathrm{OH}$ radicals, $\mathrm{NO}_{3}$ radicals and $\mathrm{O}_{3}$, respectively; cis-4methylhexa-3,5-dienal, $(1.61 \pm 0.35) \times 10^{-10},(2.17 \pm 0.30) \times 10^{-12}$ and $(4.13 \pm 0.81) \times 10^{-17}$ for reactions with $\mathrm{OH}$ radicals, $\mathrm{NO}_{3}$ radicals and $\mathrm{O}_{3}$, respectively; trans-4-methylhexa-3,5-dienal, $(2.52 \pm 0.65) \times 10^{-10},(1.75 \pm 0.27) \times 10^{-12}$ and $(5.36 \pm 0.28) \times 10^{-17}$ for reactions with $\mathrm{OH}$ radicals, $\mathrm{NO}_{3}$ radicals and $\mathrm{O}_{3}$, respectively; and 4-methylcyclohex-3-en-1-one, (1.10 \pm 0.19$) \mathrm{x}$ $10^{-10},(1.81 \pm 0.35) \times 10^{-12}$ and $(6.98 \pm 0.40) \times 10^{-17}$ for reactions with $\mathrm{OH}$ radicals, $\mathrm{NO}_{3}$ radicals and $\mathrm{O}_{3}$, respectively. Combining these measured rate constants with estimated ambient concentrations of $\mathrm{OH}$ radicals, $\mathrm{NO}_{3}$ radicals and $\mathrm{O}_{3}$ shows that these $\mathrm{C}_{7}$-carbonyls formed from mycrene, ocimene and terpinolene are all very reactive, with atmospheric lifetimes during daylight hours of approximately $1 \mathrm{hr}$ due to reaction with $\mathrm{OH}$ radicals, and, depending on the $\mathrm{NO}_{3}$ radical concentration, maybe even less during nighttime. This work has been published in the Journal of Atmospheric Chemistry, 48, 241-260 (2004).

\section{Kinetics of the Gas-Phase Reactions of $\mathrm{O}_{3}$ with a Series of Cycloalkenes}

Using a relative rate method, rate constants for the gas phase reactions of $\mathrm{O}_{3}$ with 1 - and 3-methylcyclopentene, 1-, 3- and 4-methylcyclohexene, 1-methylcycloheptene, cis-cyclooctene, 1- and 3-methylcyclooctene, 1,3- and 1,5-cyclooctadiene, and 1,3,5,7-cyclooctatetraene have been measured at $296 \pm 2 \mathrm{~K}$ and atmospheric pressure of air. The rate constants obtained (in units of $10^{-18} \mathrm{~cm}^{3}$ molecule $\mathrm{s}^{-1}$ ) are: 1-methylcyclopentene, $832 \pm 24$; 3-methylcyclopentene, $334 \pm 12$; 1-methylcyclohexene, $146 \pm 10$; 3-methylcyclohexene, $55.3 \pm 2.6$; 4-

methylcyclohexene, $73.1 \pm 3.6$; 1-methylcycloheptene, $930 \pm 24$; cis-cyclooctene, $386 \pm 23$; 1 methylcyclooctene, $1420 \pm 100$; 3-methylcyclooctene, $139 \pm 9$; cis,cis-1,3-cyclooctadiene, 20.0 \pm 1.4 ; 1,5-cyclooctadiene, $152 \pm 10$; and 1,3,5,7-cyclooctatetraene, $2.60 \pm 0.19$, where the indicated errors are two least-squares standard deviations and do not include the uncertainties in the rate constants for the reference alkenes (propene, 1-butene, cis-2-butene, trans-2-butene and 2-methyl-2-butene). This work has been published in the International Journal of Chemical Kinetics, 37, 183-190 (2005). 


\section{Review and Evaluation of Kinetic Data for the Gas-Phase Reactions of OH Radicals with Alkanes and Cycloalkanes}

The previous reviews and evaluations of Atkinson (J. Phys. Chem. Ref. Data, Monograph 1, 1-246, 1989; Monograph 2, 1-216, 1994; 26, 215-290, 1997) were completely re-evaluated and updated through early 2003. The resulting review and evaluation has been published in Atmospheric Chemistry and Physics, 3, 2233-2307 (2003).

\section{Review of the Atmospheric Chemistry of VOCs}

An invited review article dealing with the atmospheric chemistry of selected classes of VOCs (alkanes, alkenes, aromatic hydrocarbons, aldehydes, ketones, alcohols, ethers, and alkyl nitrates) was published in a thematic issue of Chemical Reviews, 103, 4605-4638 (2003).

\section{Publications arising wholly or in part from this DOE-funded contract}

Rate Constants for the Gas-Phase Reactions of a Series of Alkylnaphthalenes with the $\mathrm{OH}$ Radical

P. T. Phousongphouang and J. Arey

Environmental Science \& Technology, 36, 1947-1952 (2002).

Rate Constants for the Gas-Phase Reactions of a Series of Alkylnaphthalenes with the Nitrate Radical

P. T. Phousongphouang and J. Arey

Environmental Science \& Technology, 37, 308-313 (2003).

Rate Constants for the Photolysis of the Nitronaphthalenes and Methylnitronaphthalenes

P. T. Phousongphouang and J. Arey

Journal of Photochemistry and Photobiology A: Chemistry, 157, 301-309 (2003).

Sources of the Atmospheric Contaminants, 2-Nitrobenzanthrone and 3-Nitrobenzanthrone

P. T. Phousongphouang and J. Arey

Atmospheric Environment, 37, 3189-3199 (2003).

Methyl- and Dimethyl-/Ethyl-Nitronaphthalenes Measured in Ambient Air in Southern California

F. Reisen, S. Wheeler and J. Arey

Atmospheric Environment, 37, 3653-3657 (2003).

Characterization of Biogenic Volatile Organic Compounds and Meteorology at Azusa During the SCOS97-NARSTO

A. Reissell, C. MacDonald, P. Roberts and J. Arey

Atmospheric Environment, 37, Suppl. 2, S181-S196 (2003). 
OH Radical-Initiated Reaction of 3-Hexene-2,5-dione: Formation of Methylglyoxal

E. C. Tuazon and R. Atkinson

Environmental Science \& Technology, 37, 3339-3341 (2003).

Hydroxyaldehyde Products from Hydroxyl Radical Reactions of Z-3-Hexen-1-ol and 2-Methyl3-buten-2-ol Quantified by SPME and API-MS

F. Reisen, S. M. Aschmann, R. Atkinson and J. Arey

Environmental Science \& Technology, 37, 4664-4671 (2003).

Kinetics of the Gas-Phase Reactions of OH Radicals with Alkanes and Cycloalkanes

R. Atkinson

Atmospheric Chemistry and Physics, 3, 2233-2307 (2003)

Atmospheric Degradation of Volatile Organic Compounds

R. Atkinson and J. Arey

Chemical Reviews, 103, 4605-4638 (2003)

Rate Constants for the Gas-Phase Reactions of $\mathrm{OH}$ Radicals with a Series of Hydroxyaldehydes at $296 \pm 2 \mathrm{~K}$

J. Baker, J. Arey and R. Atkinson

Journal of Physical Chemistry A, 108, 7032-7037 (2004)

Kinetics of the Gas-Phase Reactions of $\mathrm{OH}$ Radicals, $\mathrm{NO}_{3}$ Radicals and $\mathrm{O}_{3}$ with Three $\mathrm{C}_{7^{-}}$

Carbonyls formed from the Atmospheric Reactions of Myrcene, Ocimene and Terpinolene.

J. Baker, J. Arey and R. Atkinson

Journal of Atmospheric Chemistry, 48, 241-260 (2004)

Rate Constants for the Gas-Phase Reactions of O3 with a Series of Cycloalkenes at $296 \pm 2 \mathrm{~K}$

R. D. Cusick and R. Atkinson

International Journal of Chemical Kinetics, 37, 183-190 (2005)

Formation and Reaction of Hydroxycarbonyls from the Reaction of OH Radicals with 1,3Butadiene and Isoprene

J. Baker, J. Arey and R. Atkinson

Environmental Science \& Technology, 39, 4091-4099 (2005).

Reactions of Chlorine Atoms with a Series of Aromatic Hydrocarbons

L. Wang, J. Arey and R. Atkinson

Environmental Science \& Technology, 39, 5302-5310 (2005) 